\title{
RETRACTED ARTICLE: Reexamining the impact of Tibetan snow anomalies to the East Asian summer monsoon using MODIS snow retrieval
}

\author{
Li Xu • Yueqing Li
}

Received: 26 February 2009/Accepted: 24 November 2009/Published online: 9 December 2009

(c) Springer-Verlag 2009

This article has been retracted owing to a serious copyright violation.

L. Xu $(\bowtie)$. Y. Li

Institute of Plateau Meteorology, China Meteorological

Administration, 610072 Chengdu, China

e-mail: xu_li@cma.gov.cn

L. Xu

National Climate Center, China Meteorological Administration,

100081 Beijing, China 